\title{
ASSOCIATIONS OF CONTACT HISTORY, SMOKING STATUS, NUTRITION STATUS, AND ARV TREATMENT, WITH TB-HIV CO-INFECTION AMONG PEOPLE WITH HIV/AIDS
}

\author{
Adymulianto Manurung, Rahayu Lubis, Kintoko Rochadi \\ Masters Program in Public Health, Universitas Sumatera Utara
}

\begin{abstract}
Background: Tuberculosis (TB) and HIV co-infection causes a heavy burden on health care systems and poses particular diagnostic and therapeutic challenges. Studies into predictors of TB-HIV co-infection is lacking in Indonesia. This study aimed to examine the associations of contact history, smoking status, nutrition status, and ARV treatment, with TB-HIV co-infection among people with HIV/AIDS.

Subjects and Method: This was a cross sectional study conducted in Balige, North Sumatera. A sample of 82 people living with HIV/AIDS were selected for this study, comprising 41 cases with and 41 controls without TB-HIV co-infection. The dependent variable was TB-HIV co-infection. The independent variables were contact history, smoking status, nutrition status, and ARV treatment. The data on HIV/AIDS co-infection were taken from the medical record at HKBP Committee HIV/AIDS service in Balige. Other variables were measured by questionnaire. Data were analyzed by multiple logistic regression.

Results: $82.9 \%$ of sample had no contact history, $56.1 \%$ had poor nutrition status, $78 \%$ were smokers, and $58.5 \%$ had irregular ARV treatment. TB-HIV co-infection increased with poor nutrition status $(\mathrm{OR}=3.48 ; \mathrm{p}=0.014)$, smoking status $(\mathrm{OR}=$ $3.39 ; \mathrm{p}=0.021)$, and irregular ARV treatment $(\mathrm{OR}=10.16 ; \mathrm{p}<0.001)$.

Conclusion: TB-HIV co-infection increases with poor nutrition status, smoking status, and irregular ARV treatment.

Keywords: TB-HIV co-infection, nutrition status, smoking status, ARV treatment.

\section{Correspondence:}

Adymulianto Manurung. Masters Program in Public Health, Universitas Sumatera Utara. Email: adymulianto_manurung@yahoo.com. Mobile: 085296652111.
\end{abstract}

